\title{
Características Biopsicossociais entre Acusados de Agressão Sexual contra Crianças/Adolescentes em Contextos Intra e Extrafamiliar
}

Lucilene Paiva da Costa* Orcid.org/0000-0002-1640-0530

Carlos Joaquim Barbosa da Rocha

Orcid.org/0000-0002-2378-4413

Lília Iêda Chaves Cavalcante

Orcid.org/0000-0003-3154-065

Universidade Federal do Pará, Belém, PA, Brasil

\section{Resumo}

Autores de agressão sexual a crianças e adolescentes têm recebido maior atenção por parte dos estudiosos do desenvolvimento humano. Este estudo analisou dados de 206 processos de uma vara especializada em crimes contra a criança e o adolescente, entre 2012 e 2014. O Formulário de Caracterização Biopsicossocial tornou possível o registro dos dados extraídos desses documentos. Para análise dos dados, utilizou-se estatística descritiva e o Modelo de Regressão Logística, indicando a Razão de Chance (OR) e a probabilidade da agressão sexual por contexto. Predominaram as agressões ocorridas no contexto extrafamiliar (53\%), sendo os conhecidos das famílias das vítimas os acusados mais frequentes (81\%). Já no contexto intrafamiliar, destacam-se os pais ou padrastos (53\%). Verificou-se ainda que pessoas acusadas acima dos 30 anos possuíam aproximadamente duas vezes mais chance de pertencer ao contexto intrafamiliar da vítima quando comparado aos com idade abaixo de 30 anos $(\mathrm{OR}=2,949)$. Novos estudos podem refinar as conclusões preliminares destas análises.

Palavras-chave: Agressão sexual, crianças e adolescentes, características biopsicossociais.

\section{Biopsychosocial Characteristics of Accused Child Sex Offenders in the Intrafamilial and Extrafamilial Contexts}

\begin{abstract}
Child sex offenders have been receiving increasing attention from human development researchers. The present study analyzed the data from 206 criminal prosecutions in courts specializing in crimes against children and adolescents, between 2012 and 2014. We employed a Biopsychosocial Characterization
\end{abstract}

* Endereço para correspondência: Travessa Padre Eutíquio, no 1922, Apto. 2300, Edifício Piazza Venezia, Batista Campos, Belém, PA, Brasil 66033-000. Fone: (91) 98221-1791. E-mail: lucilenepc75@gmail.com Este artigo originou-se da dissertação de Mestrado da primeira autora, intitulada Características Biopsicossociais de Autores de Agressão Sexual de Crianças elou Adolescentes em Contexto Intrafamiliar e Extrafamiliar, que foi defendida no Programa de Pós-Graduação em Teoria e Pesquisa do Comportamento da Universidade Federal do Pará (UFPA), em 2015.

Apoio: Tribunal de justiça do estado do Pará; Conselho Nacional de Desenvolvimento Científico e Tecnológico. 
Form to record the data extracted from the court documents. For data analysis, we used descriptive statistics and the Logistic Regression Model, indicating the Odds Ratio (OR) and the likelihood of sexual abuse for each context. Child sexual abuse within the extrafamilial context predominated (53\%), with acquaintances of the victims' families being the most frequent offenders $(81 \%)$. Within the intrafamilial context, parents and stepparents predominated (53\%). We also discovered that accused offenders over the age of 30 displayed two times more likelihood of belonging to the victim's intrafamilial context than those under the age of $30(\mathrm{OR}=2.949)$. Further studies will be able to refine the preliminary findings of these analyses.

Keywords: Sexual violence, children and adolescents, biopsychosocial characteristics.

\section{Características Biopsicosociales entre en los Acusados de Agresión Sexual Contra los Niños / Adolescentes en el Contexto Intra y Extra Familiar}

\section{Resumen}

Autores de violencia sexual contra los niños y los adolescentes han recibido mucha atención de los expertos del desarrollo humano. La presente investigación analizó los datos de 206 procesos de un distrito judicial especializado en ese tipo de crímenes entre 2012 y 2014. El Formulario de Caracterización Biopsicosocial posibilitó el registro de los datos extraídos de esos documentos. Para el análisis de los datos, se utilizó la estadística descriptiva y el Modelo de Regresión Logística, indicando la Razón de Chance (OR) y la probabilidad de la violencia sexual por contexto. Predominaron las agresiones ocurridas en el contexto extra familiar (53\%), en el que los conocidos de las familias de las víctimas son los acusados más frecuentes $(81 \%)$. Ya en el contexto intrafamiliar, se destacan los padres o padrastros (53\%). Se observó también que las personas acusadas que tienen más de 30 años de edad poseían aproximadamente dos veces más chance de pertenecer al contexto intrafamiliar de la víctima cuando se compara con las personas que tienen menos de 30 años $(\mathrm{OR}=2,949)$. Nuevas investigaciones pueden refinar las conclusiones preliminares de este análisis.

Palabras clave: Violencia sexual, niños y adolescentes, características biopsicosociales.

A prática da agressão sexual contra crianças e adolescentes é um problema social grave e com múltiplas repercussões. Esse tipo de agressão pode ocorrer tanto no contexto intrafamiliar quanto no extrafamiliar. No primeiro caso, a agressão sexual ocorre principalmente em ambiente doméstico - na residência da vítima ou do autor da violencia -, sendo praticada, em geral, por um parente próximo. No contexto extrafamiliar, a agressão sexual ocorre, majoritariamente, fora da residência das vítimas, sendo praticada por pessoas que não possuem vínculo de parentesco com estas (Alves, Santos, Oliveira, \& Ramos, 2013).

O estudo de Jesus e Moreira (2015) demonstrou que, no contexto intrafamiliar, a maior parte dos supostos autores de agressão sexual de crianças e adolescentes além de possuírem cônjuges e filhos, também eram empregados e desempenhavam várias atividades profissionais. A pesquisa realizada por Pincolini, Hutz, e Laskoski (2012) concluiu que o processo de tornar pública a agressão perpetrada costuma ter diversas consequências para os sujeitos envolvidos, entre elas, a ruptura de vínculos socioafetivos e a desagregação familiar, uma vez que frequentemente a violência ocorre no ambiente doméstico e envolve membros de uma mesma família.Nesse sentido, estudos mostram que o autor de agressão pode ser afastado da moradia comum ou punido com privação de liberdade. Há casos em que, com objetivo de proteger a vítima, o Juizado da Infância e Adolescência pode determinar o seu encaminhamento para instituições de acolhimento ou colocação em família substituta/estendida (Habigzang, Azevedo, Koller, \& 
Machado, 2006; Habigzang, Koller, Azevedo, \& Machado, 2005).

No contexto intrafamiliar, a agressão sexual tem sido associada à presença de atos duradouros e frequentes, cujos efeitos psicológicos podem ser ainda mais preocupantes nessas circunstâncias, posto que incluem o sentimento de culpa nutrido pelas vítimas (Chaves \& Costa, 2012; Martins \& Jorge, 2010; Pincolini \& Hutz, 2014). Outros estudos mostram que a agressão sexual caracterizada como extrafamiliar pode ocorrer em locais privados (residência do autor da agressão sexual, de terceiros ou veículo), ou em locais públicos (via pública, terreno baldio, locais de lazer) e em instituições (educativas e espaços destinados a reuniões grupais e outras atividades). Para as vítimas, as consequências sociais e psicológicas podem ser isolamento social, trauma psicológico, sentimentos de baixa autoestima e depressão (Santos \& Ippolito, 2011).

Em ambos os contextos, a agressão está relacionada ao comportamento de adultos responsáveis pelo cuidado das crianças que tiram proveito da diferença de idade, do poder, da autoridade ou da força que detêm para impor sua vontade e sobrepor seus interesses (Cerqueira \& Coelho, 2014; Guimarães \& Villela, 2011). Por isso, entende-se ser importante a realização de estudos que possam identificar e relacionar as características biopsicossociais de autores de agressão sexual nos dois contextos em que essa forma de violência tem sido estudada. Esta é uma estratégia interessante quando se quer compreender o comportamento de agressão sexual de forma contextualizada.

No contexto nacional, a literatura sobre autores de agressão sexual ainda é parca, o que pode estar refletindo na quantidade e na qualidade das políticas públicas e invervenções voltadas para esta população, sobretudo em uma perspectiva de prevenção à reicidência (Lodetti, 2010).A despeito disso,alguns trabalhos de pesquisadores brasileiros vêm demonstrando o aumento do interesse pelo tema (Chaves \& Costa, 2012; Esber, 2009; Pincolini et al., 2012; Pincolini \& Hutz, 2014; Santos et al., 2015).Contudo, importa considerar que a expansão das pesquisas referentes à agressão sexual de crianças e adolescentes é cercada de entraves colocados às fontes para ob- tenção dos dados necessários à sua realização, principalmente no que se refere aos autores da agressão sexual, pois o acesso a esse tipo de população ainda é considerado difícil. A literatura mostra que a maioria dos estudos sobre autores de agressão sexual de crianças e adolescentes é realizada com encarcerados, que se encontram sob a responsabilidade do Sistema de Justiça, no local onde residem ou praticaram a agressão sexual (Vieira, Grossi, \& Gasparotto, 2014).

Uma alternativa viável em relação aos estudos com população carcerária são as pesquisas documentais, que permitem o levantamento de informações dos autores de agressão sexual em processos jurídicos, inquéritos de investigação policial, notificações em saúde pública, entre outros. Os estudos documentais realizados no Brasil tratam, principalmente, de características sociodemográficas das vítimas e dos autores de agressão sexual (Hohendorff, Costa, Habigzang, \& Koller, 2014; Pincolini et al., 2012; Silva, Brito, Araújo, \& Abath, 2013).

Para estudar as características biopsicossociais de autores de agressão sexual têm sido realizados, com êxito, estudos baseados em fontes documentais, porque neles a coleta dos dados costuma ser feita em peças de processos policiais e jurídicos, protocolos médicos, dentre outras formas de registro, que podem oferecer dados abrangentes sobre a violência praticada. Tomando os processos jurídicos como fonte de dados, têm sido feitas pesquisas sobre as características sociodemográficas dos autores de agressão e das vítimas, bem como sobre o contexto em que a violência aconteceu.

Como exemplo desse tipo de pesquisa, cita-se o estudo descritivo documental sobre formas de agressão sexual contra meninos de Hohendorff et al. (2014), que foi realizado por meio do levantamento das notificações de violência na Coordenadoria Geral de Vigilância em Saúde de Porto Alegre, entre os anos de 2009 a 2011. Nesse estudo, analisaram-se 239 fichas de notificação de violência sexual, e os resultados demonstraram que a agressão em questão ocorreu com mais frequência no contexto intrafamiliar $(57,9 \%)$ do que no extrafamiliar $(41,3 \%)$. A residência das vítimas foi o lugar mais frequente das ocorrências no contexto intrafamiliar $(78,7 \%)$, 
enquanto que no contexto extrafamiliar foram comumente citados espaços coletivos, tais como unidades de cuidado institucional $(6,5 \%)$, via pública $(5,7 \%)$ e escolas $(5,2 \%)$. Os autores de agressão sexual de meninos foram identificados, nesse estudo, como heterossexuais, sendo a maioria do sexo masculino (93\%).

Os resultados do estudo realizado por Silva et al. (2013) sobre casos de agressões domésticas, sexuais e outras formas de violência registrados no ano de 2012, no Sistema de Informação de Agravos de Notificação (SINAN) de Recife, identificaram 3.119 casos. Nesse estudo, as vítimas eram principalmente mulheres $(67,3 \%)$, sendo que $33,6 \%$ delas pertenciam à faixa etária de zero a nove anos. Referiam-se a agressão sexual $23,9 \%$ do total de registros, que reportaram como principal autor um familiar da vítima em $69,3 \%$ dos casos e pessoas desconhecidas em $30,7 \%$. Em contrapartida, a pesquisa de Baía, Veloso, Habigzang, Dell'Aglio e Magalhães (2015), que comparou os padrões de revelação e descoberta de abuso sexual entre os estados do Rio Grande do Sul e do Pará, identificou que no primeiro estado foram mais comuns ocorrências de agressão sexual no contexto intrafamiliar $(62,41 \%)$, já no segundo predominaram ocorrências no contexto extrafamiliar $(67,7 \%)$.

O estudo documental realizado por Pincolini et al. (2012), em 229 processos criminais pertencentes a $1^{\mathrm{a}}$ e $2^{\mathrm{a}}$ Varas da Infância e Juventude de Porto Alegre, no período de 1996 a 2007, analisou as características sociodemográficas das vítimas e autores de agressão sexual, assim como os contextos de ocorrência. Os resultados da pesquisa demonstraram que a maioria dos autores deste tipo de agressão era do sexo masculino $(96 \%)$ e possuía relação com a vítima, sendo familiar ou conhecido (53\%).

Por meio de dados extraídos de fontes documentais, entende-se ser possível identificar características que definem os padrões comportamentais de autores de agressão sexual de crianças e/ou adolescentes em diferentes contextos. Neste sentido, o presente estudo objetivou analisar e comparar as características biopsicossociais de pessoas acusadas de cometer agressão sexual contra crianças e adolescentes, no contexto intrafamiliar e extrafamiliar, por meio dos processos judiciais tramitados na Vara Especializada de Crimes Contra a Criança e ao Adolescente da Comarca de Belém, no período de 2012 a 2014. Procurou-se conhecer os traços gerais que caracterizam a população pesquisada e suas implicações para o estudo desse fenômeno, com destaque para a relação entre as características biopsicossociais dos sujeitos envolvidos e os contextos em que se configurou a agressão.

\section{Método}

\section{Delineamento}

Trata-se de estudo documental, descritivo, com caráter exploratório e abordagem quantitativa.

\section{Amostra}

A realização deste estudo ocorreu por meio de consulta aos dados secundários contidos em 250 processos jurídicos, tramitados no período de 2012 a 2014, nas Varas Judiciais de três municípios do Estado do Pará (Abaetetuba, Belém e Parauapebas). Esse período foi escolhido por reunir um número significativo de processos no Sistema de Gestão de Processos Judiciais do Tribunal de Justiça do Estado do Pará (TJPA), conhecido como LIBRA. Neste estudo, optouse por analisar somente os dados do município de Belém, pois em comparação com os outros dois municípios pesquisados, este município apresentou maior concentração de processos, representando $82 \%$ do total, o equivalente a 206 processos.

\section{Instrumento}

Um Formulário de Caracterização Biopsicossocial (FCBS) produzido pela equipe da pesquisa, com base no estudo de Habigzang et al. (2005), foi utilizado na coleta de dados deste estudo. Seu uso permitiu coletar informações referentes às características biopsicossociais da população formada por acusados de agredir sexualmente crianças e/ou adolescentes, assim como registrar informações sobre as suas vítimas e a agressão sexual notificada. Organizaram-se os dados obtidos de acordo com o contexto onde ocorreu a agressão: intrafamiliar ou extrafamiliar. 
Cada um dos itens do FCBS foi desdobrado em subitens, a saber: I. Identificação do processo (número do processo, data da abertura do processo, data da ocorrência da primeira agressão sexual, data do boletim de ocorrência policial, tempo de abertura do processo); dados sociodemográficos e processuais dos acusados e das vítimas (data de nascimento, sexo, cor/ etnia, religião, situação conjugal, possuir filhos, escolaridade, vínculo de parentesco com a vítima, tipificação do ato, situação processual do acusado/a, condenações anteriores); dados das características da agressão sexual (local onde aconteceu, contexto intrafamiliar ou extrafamiliar, número de episódios da agressão sexual).

\section{Procedimentos de Coleta de Dados}

Os dados foram coletados por uma equipe de cinco pessoas a partir da leitura minuciosa dos processos judiciais de 2012 a 2014, acessados por meio do Sistema LIBRA do TJPA, na Vara Especializada de Crimes Contra a Criança e o Adolescente. Após a leitura dos documentos contidos nos processos, as informações encontradas foram registradas no FCBS.

\section{Procedimentos de Análise de Dados}

Inicialmente os dados coletados foram armazenados em uma planilha do programa Excel for Windows, em seguida, foram transportadas para o software estatístico StatisticalPackage for the Social Sciences (SPSS, versão 20), de acordo com as categorias que compõem o FCBS, instrumento utilizado na coleta de dados.Estas foram organizadas de forma binária segundo o contexto onde ocorreu a agressão sexual: intrafamiliar e extrafamiliar.

Na sequência, as variáveis analisadas foram relacionadas com cartacterísticas biopsicossociais dos acusados de praticar agressão sexual e suas vítimas, e com as características dessa forma de violência. O modelo de regressão logística binária múltipla foi utilizado na análise estatística, considerando-se como variável dependente o contexto da agressão sexual.

O modelo de regressão logística múltipla foi estimado, utilizando-se um procedimento interativo de inclusão de variáveis chamado Ste- pwise Forward não automático. A inclusão de cada variável no modelo foi verificada a partir da aplicação do teste da razão de verossimilhança e o critério de Akaike (AIC). Foram apresentadas as razões de chance (OR) e os respectivos intervalos de confiança na ordem de $95 \%$. Em todas as análises foi adotado um nível de significância de 5\%. As análises foram realizadas no software estatístico SPSS versão 20.0 for Windows.

\section{Procedimentos Éticos}

Este estudo foi aprovado pelo Comitê de Ética em Pesquisa com Seres Humanos do Núcleo de Medicina Tropical, da Universidade Federal do Pará (número 650.210, em abril de 2014), conforme Resolução de $n^{\circ} 466$, de 12 de dezembro de 2012 do Conselho Nacional de Saúde/Ministério da Saúde, a qual trata de trabalhos científicos que envolvem seres humanos.

\section{Resultados}

Dos 206 processos pesquisados, em 99 $(48,1 \%)$, os acusados da agressão sexual pertenciam ao contexto intrafamiliar e, em 107 (51,9\%), ao contexto extrafamiliar, não havendo diferença estatisticante significativa na distribuição dos casos entre os contextos $\left(X^{2}=0,311 ; g l=1 ; p=\right.$ $0,57)$. Quanto às características da agressão sexual nos contextos estudados, no que se refere ao local e o número de ocorrências das agressões, os resultados no contexto intrafamiliar foram os seguintes: a agressão ocorreu exclusivamente em local privado $(100 \%)$, principalmente, na residência das vítimas e dos acusados. Diferente do contexto extrafamiliar, em que $17 \%$ dos casos ocorreram em local público, como ruas e praças, e em $83 \%$ em locais privados, principalmente a residência dos acusados de praticar a agressão.

$\mathrm{Na}$ amostra analisada, no que concerne ao contexto extrafamiliar, $55 \%$ das agressões sexuais ocorreram uma única vez, 20\% mais de uma vez e em $25 \%$ dos casos não havia informações sobre o número de ocorrências ou tempo de duração da agressão sexual. Em relação ao contexto intrafamiliar, em $46 \%$ dos casos ocorreram mais de uma agressão, $21 \%$ foram reportados como agressão única e em 33\% não foi possível 
identificar o número de ocorrências de agressão sexual.

Neste estudo, verificou-se que nos processos havia falta de informações sobre os acusados, especialmente no que se refere à vida pregressa deles, inclusive houve a abertura de processos sem a identificação dos nomes dos acusados. Nesses casos, utilizou-se uma alcunha, ou seja, um apelido. A falta de informações ocorreu, principalmente, quando os acusados pertenciam ao contexto extrafamiliar.

Tabela 1
Nos processos analisados, identificou-se que os acusados eram, predominantemente, do sexo masculino (98\%) e tinham idade superior a 30 anos no período de abertura do processo (57\%). No contexto intrafamiliar, $76 \%$ possuíam cônjuge, diferentemente do encontrado no contexto extrafamiliar, em que $54 \%$ não apresentavam essa condição. A Tabela 1 apresenta as características sociais e também referentes à condição dos acusados em seus processos judiciais, identificando, deste modo, as características predominantes entre os acusados nos processos analisados.

Características dos Acusados de Cometer Agressão Sexual nos Contextos Intrafamiliar e Extrafamiliar

\begin{tabular}{ccc}
\hline & \multicolumn{2}{c}{$N=206$} \\
\cline { 2 - 3 } Variáveis & Intrafamiliar $(n=96)$ & Extrafamiliar $(n=110)$ \\
$\%$ & $\%$ & $\%$ \\
\hline
\end{tabular}

Idade na abertura do processo

Mais de 30 anos

Menos de 30 anos

Sexo

Masculino

Feminino

Escolaridade

Baixa escolaridade

Média e alta escolaridade

Situação conjugal

Com cônjuge

Sem cônjuge

Não

Com vínculo de parentesco

Pai ou padrasto

Outros parentes

Sem vínculo de parentesco

Conhecidos

Desconhecidos

Confessou a agressão

$\operatorname{Sim}$

Não 
De acordo com os documentos analisados, a maioria dos acusados que confessou em depoimentos ter mantido alguma forma de contato sexual com a vítima, afirmou que este fato ocorreu com o consentimento dela. Em relação à escolaridade dos acusados de agressão, no contexto intrafamiliar, pedrominou a categoria baixa escolaridade (dos anos iniciais até o ensino fundamental completo), que corresponde a $44 \%$ dos casos. Já no contexto extrafamiliar, prevaleceu a alta escolaridade (do ensino médio incompleto até o ensino superior), correspondendo a $42 \%$ dos casos.

Quanto à situação processual, a maioria dos processos encontrava-se em tramitação, uma vez que estavam em fase de apuração dos fatos, e nas situações em que os acusados foram condenados, ainda era possível haver recurso à sentença determinada em outra instância do poder judiciário. Desta forma, as pessoas mencionadas nos documentos analisados foram denominadas de acusadas e não de autoras de agressão sexual, uma vez que não havia uma sentença definitiva nos autos dos processos, além do respeito ao princípio jurídico da presunção da inocência. Este princípio é de ordem constitucional, o qual estabelece o estado de inocência como regra em relação ao acusado de prática de infração penal, até que a sentença condenatória transite em julgado na última instância do judiciário. A maior parte dos acusados respondia ao processo em liberdade, sendo esta uma realidade presente em ambos os contextos considerados pela pesquisa. A situação processual dos acusados pode ser vista na Tabela 2.

A Tabela 3 traz os resultados da estimativa feita a partir do modelo de regressão logística, referente a probabilidade de um acusado de agressão sexual pertencer ao contexto intrafamiliar.

Tabela 2

Situação Processual dos Acusados nos Contextos Intrafamiliar e Extrafamiliar

\begin{tabular}{|c|c|c|}
\hline \multirow[b]{2}{*}{ Situação dos acusados no processo } & \multicolumn{2}{|c|}{$N=206$} \\
\hline & $\begin{array}{l}\text { Intrafamiliar }(n=96) \\
\%\end{array}$ & $\begin{array}{l}\text { Extrafamiliar }(n=110) \\
\%\end{array}$ \\
\hline Absolvidos & 3 & 3 \\
\hline Processos arquivados & 1 & 2 \\
\hline Condenados & 4 & 1 \\
\hline Foragidos & 12 & 6 \\
\hline Liberdade provisória & 0 & 9 \\
\hline Respondendo em liberdade & 61 & 63 \\
\hline Preso e autuado em flagrante delito & 1 & 2 \\
\hline Prisão preventiva & 18 & 14 \\
\hline \multicolumn{3}{|c|}{$\begin{array}{l}\text { Tabela } 3 \\
\text { Modelo de Regressão Logística dos Acusados de Autoria de Agressão Sexual }\end{array}$} \\
\hline Variáveis & $P$-valor & Razão de Chance \\
\hline Idade na abertura do processo & 0,005 & 2.949 \\
\hline Situação conjugal & 0,001 & 3.557 \\
\hline Vínculo de parentesco com a vítima & 0,001 & 31.54 \\
\hline Possuir filhos & 0,001 & 3.631 \\
\hline
\end{tabular}


A razão de chance (2.949) para a variável idade na abertura do processo indicou que entre as pessoas acusadas, aquelas acima dos 30 anos, possuíam aproximadamente duas vezes mais chance de pertencer ao contexto intrafamiliar, quando comparado a outras com idade abaixo dos 30 anos. A razão de chance (3.557) indicou que os/as acusados/as com cônjuge possuíam, aproximadamente, três vezes mais chance de pertencer ao contexto intrafamiliar quando comparados com aqueles que não possuíam essa condição.

Para a variável vínculo de parentesco, a razão de chance (31.54) indicou que os acusados/ as com vínculo de parentesco com a vítima possuíam 31 vezes mais chance de pertencer ao contexto intrafamiliar e a razão de chance (3.631) indicou que os acusados/as com filhos possuíam cerca de três vezes mais chance de pertencer ao contexto intrafamiliar, quando comparado a outros sem filhos. O modelo de regressão logística foi utilizado para estimar também a probabilidade de ocorrência de agressão sexual contra crianças e adolescentes, de acordo com o contexto reportado. A Tabela 4 demonstra a probabilidade de ocorrência de agressão sexual no contexto intra ou extrafamiliar diante da presença de determinadas características.

\section{Tabela 4}

Probabilidades de Ocorrência de Agressão Sexual de acordo com o Contexto Intrafamiliar e Extrafamiliar

\begin{tabular}{|c|c|c|c|c|c|}
\hline Contexto & $\begin{array}{l}\text { Idade na abertura } \\
\text { do processo }\end{array}$ & $\begin{array}{l}\text { Situação } \\
\text { conjugal }\end{array}$ & $\begin{array}{l}\text { Parente } \\
\text { da vítima }\end{array}$ & $\begin{array}{l}\text { Possuir } \\
\text { filhos }\end{array}$ & $\begin{array}{c}\text { Probabilidade } \\
(\%)\end{array}$ \\
\hline \multirow[t]{7}{*}{ Intrafamiliar } & Acima de 30 & Com cônjuge & Sim & Sim & 95,45 \\
\hline & Acima de 30 & Com cônjuge & Sim & Não & 93,37 \\
\hline & Abaixo de 30 & Com cônjuge & Sim & Não & 94,69 \\
\hline & Acima de 30 & Com cônjuge & Sim & Sim & 96,37 \\
\hline & Abaixo de 30 & Sem cônjuge & Sim & Não & 90,62 \\
\hline & Abaixo de 30 & Sem cônjuge & Sim & Não & 88,41 \\
\hline & Abaixo de 30 & Sem cônjuge & Sim & Sim & 93,50 \\
\hline \multirow[t]{7}{*}{ Extrafamiliar } & Acima de 30 & Com cônjuge & Não & Não & 35,43 \\
\hline & Acima de 30 & Sem cônjuge & Não & Não & 22,91 \\
\hline & Abaixo de 30 & Sem cônjuge & Não & Não & 27,33 \\
\hline & Abaixo de 30 & Sem cônjuge & Não & Sim & 30,66 \\
\hline & Abaixo de 30 & Sem cônjuge & Não & $\operatorname{Sim}$ & 35,89 \\
\hline & Abaixo de 30 & Com cônjuge & Não & Não & 40,98 \\
\hline & Abaixo de 30 & Com cônjuge & Não & Sim & 50,82 \\
\hline
\end{tabular}

Nota. Em negrito, maior probabilidade de um acusado de agressão sexual pertencer ao contexto intra ou extrafamiliar de acordo com as variáveis que compuseram o modelo de regressão logística.

De acordo com a Tabela 4, a probabilidade de ocorrência de agressão sexual contra crianças e adolescentes no contexto intrafamiliar foi de $96,37 \%$, na presença das seguintes características: possuir idade acima de 30 anos, ter cônjuge e filhos, além de vínculo de parentesco com a vítima. No contexto extrafamiliar, a maior pro- babilidade alcançada foi de $50,82 \%$, quando os acusados possuíam abaixo de 30 anos, sendo que não possuíam cônjuge, filhos e nem vínculo de parentesco com as vítimas. Esses resultados encontrados não podem ser generalizados para a população de autores de agressão sexual em geral, são específicos da amostra estudada. 


\section{Discussão}

Neste estudo, dos 206 processos pesquisados, a maior parte das ocorrências de agressão sexual referia-se ao contexto extrafamiliar. Esta distribuição diverge do que tem sido observado em estudos internacionais (Langevin \& Curnoe, 2012) e da região Centro-sul do Brasil (Martins \& Jorge, 2010; Pincolini \& Hutz, 2014; Serafim, Saffi, Achá, \& Brarros, 2011), uma vez que os levantamentos têm apontado o predomínio de casos de agressão sexual no contexto intrafamiliar.Em oposição, nota-se que os resultados aqui apresentados corroboram com estudos anteriores realizados no Norte e no Nordeste do Brasil (Baía et al., 2015; Maia \& Barreto, 2012; Santos et al., 2015), o que pode sugerir a existência nessas regiões de um padrão próprio de distribuição dos casos de agressão sexual entre os contextos intra e extrafamiliar, supostamente com a presença majoritária de casos ocorridos fora do ambiente familiar.

Em que pese não haver diferença estatisticamente significativa entre o percentual de acusados dos contextos intra e extrafamiliar neste estudo, sabe-se hoje que quando há vínculo de parantesco entre a vítima e o autor de agressão e estes coabitam, a revelação da agressão sexual pela vítima tem sido descrita como mais difícil e menos comum (Baía et al., 2015). No contexto intrafamiliar, a denúncia da agressão sexual tem estado condicionada à descoberta acidental ou testemunhal, sendo este inclusive o padrão de revelação mais comum em uma amostra pesquisada no estado do Pará, como o demonstrado por Baía et al. (2015).

Nesse sentido, a revelação de agressão sexual intrafamiliar ganha contornos de maior complexidade, o que torna supostamente a sua notificação mais difícil, posto que, nestes casos,os demais membros da família podem estar também expostos a relações violentas. Sobre esse assunto, Lavoratti e Silvestre (2013) afirmam que na maior parte das culturas a organização familar se assenta sobre uma estrutura patriarcal, reproduzindo desigualdades baseadas no gênero e na idade. Assim, prosseguem as autoras, a agressão sexual de uma criança ou um adolescente que ocorre no ambiente familiar, com frequência, costuma ser mais uma expressão da violência generalizada que atinge os demais membros da família e afeta as suas relações, inclusive as mães também podem estar sendo vítimas de violência física, sexual e/ou psicológica, dificultando os seus posicionamentos em face da agressão sexual praticada contra seus filhos.

Outro aspecto a ser considerado nessa discussão é que a ocorrência e o silêncio em torno da agressão sexual contra crianças e adolescentes no contexto intrafamiliar pode estar relacionada com a síndrome de acomodação. Summit (1983) define essa síndrome como um conjunto de cinco aspectos, sendo que dois deles colocam a criança em uma situação de vulnerabilidade à agressão sexual (segredo e desamparo) e as outras três são decorrentes das relações incestuosas já consumadas (aprisionamento e acomodação; revelação retardada, conflitada e não convincente; e retração). Na dinâmica da relação abusiva, a criança é constrangida a firmar um pacto de silêncio sobre as práticas sexuais incestuosas, frequentemente, com argumentos de que ninguém acreditará no seu relato e que, caso resolva revelar o segredo, sobrevirá sobre ela própria, sobre o autor de agressão e sobre as pessoas que lhe são queridas consequências desastrosas, como a morte, a separação, a perda do apreço e carinho e a destruição da família. Nessas circunstâncias, a criança se sente desamparada, acredita que nada pode ser feito para interromper as agressões e, assim, passa a se "acomodar" à situação, aceitando resignadamente a agressão sofrida.

Conforme Summit (1983), essa configuração pode retardar significativamente a revelação ou descoberta da agressão sexual intrafamiliar e, quando esta ocorre, é possível que a vítima não desperte a confiança da família ou da sua rede de apoio, tendo como consequências a apresentação de relatos inconsistentes ou a negação das agressões sofridas (retração), o que dificulta a responsabilização do autor de agressão e a interrupção do ciclo de violência. Nesses termos, admite-se que a síndrome de acomodação pode vincular-se à síndrome de segredo e a síndrome de adição, relacionando-se entre si de forma dinâmica.Deste modo, conforme Furnis (1993), o segredo es- 
taria diretamente relacionado com a situação de controle do autor da agressão que, por saber que seu comportamento sexual gera intenso repúdio social, procura manifestar, em relação à vítima, comportamentos incompatíveis com agressão sexual praticada na frente de terceiros e, na privacidade da relação abusiva, coage, ameaça ou seduz a vítima para garantir a manutenção do segredo. A síndrome de adição é caracterizada pelo comportamento impulsivo diante da possibilidade de praticar a agressão sexual gerando dependência.

No contexto extrafamiliar, porém, a configuração relacional entre o autor de agressão, a vítima e sua família, apresentada nos prágrafos anteriores, não é comum. A mãe (ou outro cuidador) da criança ou do adolescente, bem como as próprias vítimas e outros familiares, muitas vezes, não possuem relação de dependência afetiva ou financeira com o autor de agressão, nem mesmo histórico de vitimização por outros tipos de violência, o que facilita a denúncia da agressão sexual quando identificada. Além disso, o processo de revelação da violência sofrida por parte da vítima costuma ser mais comum e mais rápido quando comparado com o contexto intrafamiliar, pois as vítimas tendem a receber maior crediblidade e suporte materno (Baía, Magalhães, \& Veloso, 2014).

Dando continuidade à discussão dos resultados, diz-se que este estudo também corrobora achados de levantamentos anteriores no que se refere às variáveis idade e vínculo de parentesco com as vítimas (Lussier, Bouchard, \& Beauregard, 2011; Martins \& Jorge, 2010; Pincolini \& Hutz, 2014; Rebocho \& Gonçalves, 2012). Tais estudos demonstraram que no contexto intrafamiliar os autores de agressão sexual eram mais velhos e com frequência possuíam filhos e cônjuge.

Em contraste, no contexto extrafamiliar, prevaleceram acusados mais jovens, solteiros e que têm preferência por vítimas adolescentes. $\mathrm{Na}$ região Amazônica, localizada no Norte do Brasil, é comum a relação de homens mais velhos com adolescentes, especialmente na zona rural, em que é mais acentuada a situação de pobreza e escassa a oferta de serviços e políticas públicas de suporte às famílias, sendo o estabelecimento dessas relações, para as adolescentes, uma alternativa à privação econômica, ao trabalho doméstico exaustivo e a violência doméstica (Taylor, Lauro,Segundo, \& Greene, 2015). Tal característica cultural contrasta, porém, com os dispositivos legais que podem tipificar esses relacionamentos como estupro de vulnerável, principalemente após a promulgação da Lei $12.015 / 2009$. Desta forma, é comum os acusados do contexto extrafamiliar não se reconhecerem como autores de agressão sexual, justificando que a relação estabelecida com a adolescente é de natureza consentida.

Diversas pesquisas (Hohendorff et al., 2014; Pincolini et al., 2012; Silva et al., 2013) apresentam resultados semelhantes aos encontrados neste estudo no que se refere ao local de ocorrência das agressões sexuais. Neste sentido, identificou-se que, tanto no contexto intrafamiliar quanto no extrafamiliar, essas agressões teriam ocorrido principalmente em locais privados, sobretudo, em residências (das vítimas, dos acusados da autoria da agressão ou de ambos, quando coabitavam). Apenas no contexto extrafamiliar foram identificadas acusações de ocorrências da agressão em estudo no interior de veículos e locais públicos ou ermos.

O estudo de Lussier et al. (2011) indicou que no contexto intrafamiliar os autores de agressão sexual costumam manter vítimas únicas que podem ser repetidamente violentadas. No contexto mencionado, há evidências de que o autor da agressão apresenta maior capacidade de retardar a descoberta desse comportamento. Diferentemente do observado no contexto extrafamiliar, em que esses sujeitos fazem um número maior de vítimas, pois, em geral, praticam uma agressão por vítima e possuem menor capacidade de retardar a descoberta da violência perpetrada.

No que se refere à situação processual do autor de agressão sexual, foi possível verificar que a maioria dos processos se encontravam em tramitação, posto que,não havia ainda uma sentença estabelecida. Nesses termos, a Constituição Federal de 1988, em seu artigo $5^{\circ}$, inciso LVII, impede que denunciados por esse tipo de crime 
sexual sejam considerados autores agressão, uma vez que "Ninguém será considerado culpado até o trânsito em julgado de sentença penal condenatória" (Constituição da República Federativa do Brasil, 1988). Sendo assim, enquanto existir a possibilidade de recursos nas instâncias judiciais os réus em regra são inocentes. O estudo de Pincolini e Hutz (2014), sobre autores de agressão sexual no sul do Brasil, concluiu que recorrer à instância de $2^{\circ}$ Grau foi vantajoso para os réus na maior parte dos casos, pois, pelo observado, muitos autores de agressão sexual condenados acabaram conquistando o direito de recorrer das sentenças determinadas em liberdade.

Neste estudo, foi possível ainda observar que os acusados pertenciam, predominantemente, ao sexo masculino nos dois contextos estudados. De acordo com Martins e Jorge (2010), o sexo masculino é apontado como predominante entre autores de agressão sexual, e este traço predominante nessa população reforça a perscpectiva de gênero que caracteriza esse tipo de violência. Pelo exposto, supõe-se que a ocorrência da agressão sexual no contexto intrafamiliar e extrafamiliar acarreta sérias consequências para o desenvolvimento das vítimas e também para os autores de tal agressão.

Os dados encontrados neste estudo podem auxiliar na criação de estratégias de prevenção e elaboração de políticas voltadas para o atendimento de pessoas envolvidas nesse tipo de agressão, em especial no Norte do país. Como se sugere neste e em outros estudos (Baía et al., 2015; Maia \& Barreto, 2012), essa região possui certas particularidades em relação a distribuição de casos de agressão nos contextos intra e extrafamiliar.

Levando-se em consideração os dados encontrados neste artigo, fica mais clara a importância de se propor e implementar políticas públicas voltadas para prevenção desse tipo de violência, além da proposição de intervenções que se pautem pelas características específicas de populações como as que foram envolvidas neste estudo. Em particular, entende-se ser necessário o acompanhamento psicossocial dos autores de agressão concomitante a aplicação da pena, tendo em vista que a revelação da violên- cia perpetrada e a punição prevista a esse tipo de comportamento também podem lhe causar sofrimento. Muitos desses homens tiveram uma vida de privações de figuras de referências positivas, de cuidado e afetividade, implicando em uma organização subjetiva disfuncional e na manifestação de comportamentos socialmente reprováveis e juridicamente puníveis. Logo, se não há nenhuma intervenção voltada para a saúde mental desses sujeitos, que lhe permita a ressignificação de suas histórias de vida, falha-se na proposta de uma política de prevenção efetiva, pois os agentes das práticas agressivas estão excluídos dessas políticas e a ênfase continua a ser uma política de reparação, ao se trabalhar exclusivamente com as vítimas e suas famílias.

\section{Considerações Finais}

Ainda que o objetivo deste estudo tenha sido alcançado, deve-se mencionar que a ausência de várias informações sobre as características psicossociais da população estudada nos processos analisados. Essa ausência foi especialmente observada nos processos em que o acusado pertencia ao contexto extrafamiliar.

Esta dificuldade pode ser vista, portanto, como uma limitação deste estudo. A escassez de pesquisas nacionais e regionais sobre a população estudada, pode ter limitado a discussão dos achados e sua comparação com outras pesquisas. Por isso, considera-se relevante a realização de mais pesquisas sobre a temática trabalhada, tanto do ponto de vista quantitativo (prevalência e características) quanto qualitativo (trajetória de vida). Estudos qualitativos com a população de autores de agressão sexual de crianças e adolescentes poderiam contribuir decisivamente para a compreensão dos fatores motivadores da ocorrência da agressão sexual no contexto intrafamiliar e extrafamiliar, bem como na proposição de intervenções que possuam uma perspectiva preventiva e terapêutica.

Outra possibilidade seria a realização de estudos longitudinais, que facilitariam o esclarecimento das relações entre a prática da agressão sexual no contexto intrafamiliar e extrafamiliar e a reincidência. Os resultados de estudos desta 
natureza podem vir a ser utilizados pelo sistema prisional e por outros órgãos governamentais e não governamentais, constituindo-se em valiosos subsídios para nortear intervenções junto a autores de agressão sexual e, assim, prevenir a recorrência da agressão sexual.

\section{Referências}

Alves, A. D. N., Santos, J. M. S., Oliveira, J. S. A., \& Ramos, R. S. (2013). Conselho tutelar e abuso sexual: Ocorrências em crianças e adolescentes. Revista de Enfermagem, 7(1), 135-142. doi:10.5205/reuol.3049-24704-1LE.0701201319

Baía, P. A., Magalhães, C. M. C., \& Veloso, M. M. X. (2014). Caracterização do suporte materno na descoberta e revelação do abuso sexual infantil. Temas em Psicologia, 22(4), 691-700. doi:10.9788/TP2014.4-02

Baía, P. A. D., Veloso, M. M. X., Habigzang, L. F., Dell'Aglio, D. D., \& Magalhães, C. M. C. (2015). Padrões de revelação e descoberta do abuso sexual de crianças e adolescentes. Revista de Psicología, 24(1), 1-19. doi:http://dx.doi. org/10.5354/0719-0581.2015.37007

Cerqueira, D., \& Coelho., D. S. C. (2014). Estupro no Brasil: Uma radiografia segundo os dados da Saúde (Nota Técnica $\mathrm{N}^{\circ} 11$ ). Brasília, DF: Instituto de Pesquisa Econômica Aplicada. Recuperado em http://www.ipea.gov.br/portal/ images/stories/PDFs/nota_tecnica/140327 notatecnicadiest11.pdf

Chaves, E., \& Costa, L. F. (2012). Estudo técnico sobre o afastamento do agressor do lar no abuso sexual: Autor, família e vítima. Psicologia: Teoria e Prática, 14(2), 102-115. Recuperado em http://editorarevistas.mackenzie.br/index.php/ ptp/article/view/4776/3682

Constituição da República Federativa do Brasil. (1988). Recuperado em http://www.planalto. gov.br/ccivil 03/constituicao/constituicao.htm

Esber, K. M. (2009). Autores de violência sexual contra crianças e adolescentes. Goiás, GO: Canone.

Furnis, T. (1993). Abuso sexual da criança: Uma abordagem multidisciplinar. Porto Alegre, RS: Artes Médicas.

Guimarães, J. A. T. L., \& Villela. W. V. (2011). Características da violência física e sexual contra crianças e adolescentes atendidos no IML de
Maceió, Alagoas, Brasil. Cadernos de Saúde Pública, 27(8),1647-1653. Recuperado em http://www.scielosp.org/pdf/csp/v27n8/19.pdf

Habigzang, L. F., Azevedo, G. A., Koller, S. H., \& Machado, P. X. (2006). Fatores de risco e de proteção na rede de atendimento a crianças e adolescentes vítimas de violência sexual. Psicologia: Reflexão e Crítica, 19(3), 379-386.

Habigzang, L. F., Koller, S. H., Azevedo, G. A., \& Machado, P. X. (2005). Abuso sexual infantil e dinâmica familiar: Aspectos observados em processos jurídicos. Psicologia: Teoria e Pesquisa, 21(3), 341-348. Recuperado em http://www. scielo.br/pdf/ptp/v21n3/a11v21n3.pdf

Hohendorff, J. V., Costa, L. S., Habigzang, L. F., \& Koller, S. H. (2014). Análise documental de casos de violência sexual contra meninos notificados em Porto Alegre. Paidéia (RibeirãoPreto), 24(58), 187-196. doi:http://dx.doi. org/10.1590/1982-43272458201406

Jesus, A. P. C., \& Moreira, R. B. R. (2015). A violência sexual contra crianças e adolescentes no Brasil: Da proteção jurídica as políticas públicas. Seminário Internacional de Demandas Sociais e Politicas Públicas na Sociedade Contemporânea. Recuperado em http://online. unisc.br/acadnet/anais/index.php/sidspp/article/view/13166/2249

Langevin, R., \& Curnoe, S. (2012). Lifetime criminal history of sex offenders seen for psychological assessment in Five decades. International Journal of Offender Therapy and Comparative Criminology, 56(7), 997-1021. doi:10.1177/0306624X11420084

Lavoratti, C., \& Silvestre, L. P. (2013). O reflexo das relações de gênero no cotidiano da violência sexual intrafamiliar contra crianças e adolescentes. DILEMAS: Revista de Estudos de Conflito e Controle Social, 6(4), 645-674.

Lei Federal 12.015 de agosto de 2009. (2009). Recuperado em http://www.planalto.gov.br/ccivil_03/ato2007-2010/2009/lei/112015.htm

Lodetti, A. S. (2010). Homens encarcerados por violência sexual: Um estudo sobre enunciação e performatividade (Dissertação de mestrado). Programa de Pós-Graduação em Psicologia, Universidade Federal de Santa Catarina, Florianópolis, SC, Brasil. Recuperado em https://repositorio.ufsc.br/bitstream/handle/123456789/93981/282994. pdf? sequence $=1 \&$ is Allowed $=y$ 
Lussier, P., Bouchard, M., \& Beauregard, E. (2011). Patterns of criminal achievement in sexual offending: Unravelling the "successful" sex ofender. Journal of Criminal Justice, 39, 433-444. doi:10.1016/j.jcrimjus.2011.08.001

Maia, A. C., \& Barreto, M. (2012). Violência contra crianças e adolescentes no Amazonas: Análise dos registros. Psicologia em Estudo, 17(2), 195-204. doi:http://dx.doi.org/10.1590/S141373722012000200003

Martins, C. B. G., \& Jorge, M. H. P. M. (2010). Abuso sexual na infância e adolescência: Perfil das vítimas e agressores em um município do sul do brasil. Texto Contexto Enfermagem, 19(2), 246255. Recuperado em http://www.scielo.br/pdf/ tce/v19n2/05.pdf

Pincolini, A. M. F., \& Hutz, C. S. (2014). Abusadores sexuais adultos e adolescentes no sul do Brasil: Pesquisa em denúncias e sentenças judiciais. Temas em Psicologia, 22(2), 301-312. doi:10.9788/TP2014.2-03

Pincolini, A. M. F., Hutz, C. S., \& Laskoski, L. (2012). Caracterização da violência sexual a partir de denúncias e sentenças judiciais. Psicologia em Pesquisa, 6(1), 19-28. Recuperado em http://pepsic.bvsalud.org/pdf/psipesq/v6n1/ v6n1a04.pdf

Rebocho, M. F., \& Gonçalves, A. (2012). Sexual predators and prey: A comparative study of the hunting behavior of rapists and child molesters. Journal of Interpersonal Violence, 27(14), 2770-2789. doi:10.1177/0886260512438280

Santos, C. A., Costa, M. C. O., Amaral, T. R., Nascimento, C. L. N., Sobrinho, Musse, J. O., \& Costa, A. M. (2015). Agressor sexual de crianças e adolescentes: Análise de situações relacionadas à violação e vítimas. Adolescência \& Saúde, 12(3), 7-20. Recuperado em http://www.adolescenciaesaude.com/detalhe_artigo.asp?id=519

Santos, B. R., \& Ippolito, R. (2011). Guia escolar: Identificação de sinais de abuso e exploração sexual de crianças e adolescentes. Soropédica, RJ: Editora da Universidade Federal Rural do Rio de Janeiro. Recuperado em http://portaldoprofessor.mec.gov.br/storage/materiais/0000016936.pdf

Serafim, A. P., Saffi, F., Achá, M. F. F., \& Brarros, D. M. (2011). Dados demográficos, psicológicos e comportamentais de crianças e adolescentes vítimas de abuso sexual. Revista Psiquiatria Clínica, 38(4), 143-147. Recuperado em http://www. scielo.br/pdf/rpc/v38n4/a06v38n4.pdf

Silva, M. C. M., Brito, A. M., Araújo, A. L., \& Abath, M. B. (2013). Caracterização dos casos de violência física, psicológica, sexual e negligências notificados em Recife, Pernambuco, 2012. Epidemiologia e Serviçosde Saúde, 22(3),403-412. Recuperado em http://scielo. iec.pa.gov.br/pdf/ess/v22n3/v22n3a05.pdf

Summit, R. C. (1983). The child sexual abuse accomodation syndrome. Child Abuse \& $\mathrm{Ne}$ glect, 7(2), 177-193. Retrieved from http:// www.abusewatch.net/Child $\% 20$ Sexual $\% 20$ Abuse \%20Accommodation\%20Syndrome.pdf

Taylor, A. Y., Lauro, G., Segundo, M., \& Greene, M. E. (2015). Ela vai no meu barco. Casamento na infância e adolescência no Brasil. Resultados de pesquisa de método misto. Rio de Janeiro, RJ: Instituto Promundo \& Promundo.

Vieira, M. S., Grossi, P. K., \& Gasparotto, G. P. (2014). A violência sexual infanto-juvenil e o olhar dos profissionais da rede de enfrentamento: Notas críticas acerca do cenário do município de Porto Alegre. Seminário Internacional de Demandas Sociais e Políticas Públicas na Sociedade Contemporânea, (11). Recuperado em http://online.unisc.br/acadnet/anais/index.php/sidspp/article/view/11750/1544

(C) $\mathrm{O}(\mathrm{s})$ autor(es), 2018. Acesso aberto. Este artigo está distribuído nos termos da Licença Internacional Creative Commons Atribuição 4.0 (http://creativecommons.org/licenses/by/4.0/), que permite o uso, distribuição e reprodução sem restrições em qualquer meio, desde que você dê crédito apropriado ao(s) autor(es) original(ais) e à fonte, fornecer um link para a licença Creative Commons e indicar se as alterações foram feitas.

Recebido: $25 / 09 / 2016$

$1^{a}$ revisão: $17 / 01 / 2017$

$2^{a}$ revisão: $21 / 02 / 2017$

Aceite final: $28 / 02 / 2017$ 